\title{
O PÁTIO DA ESCOLA: ESPAÇO DE SOCIALIZAÇÃO
}

\author{
Maria Luísa Guillaumon Emmel*
}

\section{RESUMO.}

Este trabalho teve por objetivo realizar um estudo sobre as formas de interação entre crianças escolares e desenvolver uma programação de atividades lúdicas para serem executadas no pátio de uma escola rural da região de São Carlos (Estado de São Paulo), nos horários de recreio. Aproximadamente 200 crianças na faixa etária compreendida entre os 7 e 10 anos foram beneficiadas com este programa, que teve a duração de um ano. Após a intervenção, cada atividade aplicada foi avaliada segundo sua eficácia no desenvolvimento da competência social das crianças. Os resultados mostraram que a proposta colocada em prática atendeu às expectativas, destacando-se, entre outros:1) o crescimento do índice de participação das crianças à medida que as sessões de brincadeiras eram oferecidas;2) a progressiva participação de meninas em brincadeiras tidas como masculinas e da participação de meninos em brincadeiras rotuladas como femininas;3) a progressiva permanência de meninas em áreas do pátio antes frequentadas exclusivamente por meninos e vice-versa;4) a ocorrência de interações entre os sexos e entre crianças que não se conheciam;5) o aumento da cooperação entre os grupos durante as brincadeiras;6) os relatos de professores indicando melhoras no comportamento dentro da sala de aula após o recreio;7) a diminuição acentuada dos comportamentos anti-sociais observados no pré teste.

\section{APRESENTAÇÃo}

A origem desse trabalho deu-se em final de 1991, quando a autora atuava em uma escola rural da região de São Carlos, desenvolvendo um outro

* Prof. Dra. Universidade Federal de São Carlos- Departamento de Terapia Ocupacional.

** Registre-se os agradecimentos às alunas: ADRIANA PAOLETTI POSSO, CARLA CILENE BAPTISTA DA SILVA, EVA GERTRUDES TORELLI, ANA ELISA TORRES REHDER, KEILA PIMENTA, SIMONE CRISTINA SIMÕES PASSOS, MÁRCIA MINATOGAWA, LUCIANA LOPES e KÁTIA MOEDA KANOSKI, do curso de Terapia Ocupacional da UFSCar, que atuaram como coordenadoras dos grupos de brincadeiras.

Paidéia, FFCLRP-USP, Rib. Preto, Fev/Ago 96. 
projeto de pesquisa. Naquela ocasião, observações assistemáticas mostravam que a dinâmica interacional nos horários de recreio estava longe de ser considerada adequada. $\mathrm{O}$ grande número de crianças correndo freneticamente sem uma finalidade aparente, outras gritando sem razão, foram alguns dos comportamentos que se fizeram presentes e nos chamaram a atenção, indicando que "algo não ia bem" dentro daquele espaço de tempo que, a princípio, deveria servir como um período de descanso das atividades escolares e de preparação para a próxima etapa do dia na escola. Começamos então a questionar o "porque" daqueles comportamentos aparentemente sem sentido estarem ocorrendo com tanta frequência. A nosso ver, esse intervalo deveria ser ocupado com atividades lúdicas, que propiciassem não só uma satisfação pessoal, mas também um contato mais intenso com seus colegas, atividades essas restritas dentro da sala de aula pelas exigências inerentes ao tipo de trabalho a que se propõe o ensino formal naquela instituição.

Essa curiosidade, somada às experiências de outros estudos que já vinham identificando a necessidade de se aproveitar o horário do recreio com atividades que promovessem o desenvolvimento dos alunos em áreas que não são tradicionalmente trabalhadas dentro do espaço escolar, instigou o interesse para o desenvolvimento deste trabalho com essa população específica.

\section{BRINCADEIRA, INTERAÇÃO SOCIAL E DESENVOLVIMENTO INFANTIL.}

Há evidências de que as brincadeiras, antes de servirem de simples distração, constituem-se em um campo laboratorial de experiências de vida para a criança. $O$ estudo de sua influência para o desenvolvimento infantil tem sido objeto de investigação de pesquisadores ligados a várias linhas de pensamento, tendo-se como ponto de partida o pressuposto de que são atividades imprescindíveis para o desenvolvimento social, afetivo, motor e cognitivo das crianças.

Havighurst (1953) inclui as brincadeiras nas chamadas "tarefas de desenvolvimento". Uma das características das tarefas de desenvolvimento é que elas têm uma época específica na vida para a sua aquisição - momentos próprios para a introdução de sua aprendizagem e para a sua força potencial na aceitação social da pessoa. Mas isso não ocorre com certas tarefas. Há algumas que nunca terminam; elas acontecem durante um longo periodo de tempo, variando em aspectos específicos. São as chamadas tarefas recorrentes. Aprender a fazer amizades e a conviver com outras pessoas é um exemplo dessa modalidade. Elas têm início muito cedo, para a maioria das pessoas ao entrar na escola. Mas 
na puberdade elas começam a mudar sua natureza e a entrar em uma nova fase, de aprender a contatar com pares do sexo oposto. Mais tarde - uma outra fase a de aprender a conviver com pessoas de ambos os sexos de uma forma socialmente madura, onde uns cooperam com os outros, não só por causa da amizade, mas por alguma proposta impessoal. A pessoa idosa novamente se vê face a uma nova etapa, onde tem que aceitar os desafios impostos pelo tempo e se associar aos outros idosos da sociedade, aprender a conviver com a perda do companheiro, a relacionar-se com os mais jovens, etc.

Com as atividades de lazer ocorre a mesma coisa. As necessidades dessas atividades, embora sejam valorizadas basicamente na infância, podem se estender por toda a vida. É evidente que de acordo com a etapa da vida, as necessidades e as formas de brincar vão ser diferentes. No entanto, estas se constituem em tarefas importantes para o desenvolvimento e a manutenção de vida e estão classificadas dentro das chamadas Tarefas Recorrentes.

Nas brincadeiras, desde que desempenhadas em grupos, pode-se observar o estabelecimento de uma rede de relações. Vale lembrar que a estrutura interacional é essa rede de relações que se depreende dos comportamentos das crianças em uma situação de grupo, com movimentos que se traduzem em aproximações e afastamentos entre as crianças, ou de adultos que eventualmente estejam presentes.

$\mathrm{Na}$ fase entre os 7 e os 10 anos, as atividades grupais são determinantes de interações sociais positivas. É através delas que a competência social das crianças é desenvolvida e aprimorada (Emmel, 1990). Em um estudo conduzido por Branco (1989), as atividades livres foram as que mais propiciaram o estabelecimento de interações sintônicas entre crianças, caracterizadas pela compatibilidade de interêsses ou disposições afiliativas, favorecendo interações mais longas e mais frequentes.

Jones (1981) observou diferenças sexuais na performance social de crianças pequenas, como por exemplo o fato das meninas passarem mais tempo perto de outras crianças sem interagir, enquanto os meninos passam mais tempo observando outras crianças de longe. Um outro aspecto apontado por esse autor é o da variabilidade da qualidade das interações sociais proporcionalmente a passagem do tempo. Ele observou que a sociabilidade aumenta com a idade. $\mathrm{O}$ estudo de Emmel (1990) demonstrou diferenças qualitativas nas interações mantidas entre crianças mais novas e mais velhas (7-8 e 9-10 anos). No grupo de crianças mais velhas, a sequenciação e complexidade dos diálogos, bem como a combinação de várias modalidades interativas em cada surto ocorrido (linguagem, somada a trocas de olhares, sorrisos, gesticulações), foi superior ao grupo de crianças mais novas, mostrando um nível de elaboração bem mais

Paidéia, FFCLRP-USP, Rib. Preto, Fev/Ago 96. 
aprimorado. Neste mesmo estudo, observou-se nas crianças mais novas, a predominância de diálogos curtos e interrompidos e de brincadeiras turbulentas, como lutas corporais, o que gerou um maior número de interrupções nas atividades que estavam sendo executadas, comparadas às crianças mais velhas.

Piaget (1973) utiliza o termo "jogo" para designar o brinquedo. O jogo é considerado como parte dos processos de assimilação e acomodação, que desencadeiam a relação e incorporação da criança no mundo. Os jogos com regras, que aparecem em torno dos 7 anos e se desenvolvem durante toda a vida, permitem que a criança domine o raciocínio operatório a partir de situações concretas e realize processos mentais reversíveis.

Os estudos dos autores citados acima, foram sendo complementados com pesquisas interdisciplinares, demonstrando que $o$ ato de brincar sofre intensa influência da cultura na qual a criança está inserida. Na literatura brasileira, os trabalhos de Kishimoto (1992), Biasoli-Alves (1992), Martinez (1992), Pierre e Kubo (1990), dentre outros, além de compor um campo de informações de naturezas distintas, com estudos descritivos, experimentais e correlacionados, demontram a importância das relações entre o brincar, o desenvolvimento e a aprendizagem da criança.

\section{O BRINCAR NA ESCOLA}

A entrada da criança na escola, aqui representada pelo primeiro grau formal, significa também uma grande redução nas brincadeiras. As tarefas escolares e o estudo ganham uma importância muito acentuada; a criança passa a maior parte do seu dia na posição sentada, sem direito a movimentos mais livres e amplos, numa atitude que se opõe à sua condição natural de desenvolvimento, que solicita, justamente, a atividade motora. Bruscamente, ela é submetida a uma mudança radical, passando de hábitos de movimentação ampla para posições fixas; de atividades e ações concretas para um mundo novo e abstrato.

A hora do recreio, que seria de se esperar como o momento de liberação da energia acumulada, da atividade lúdica, é um período que também tem suas limitações. Em algumas escolas as crianças sequer saem de suas carteiras: apenas recebem o lanche, comem e continuam a atividade de classe. Quando há um recreio, no pátio as brincadeiras que envolvem movimentação global, como o pega-pega, os jogos de bola, etc, são em geral reprimidas com veemência. As áreas disponíveis para o recreio, por sua vez, não oferecem opções para atividades lúdicas mais tranquilas. Na maioria das escolas o que se vê são pátios, ou pequenos, ou sem planejamento algum para quaisquer brincadeiras, reservando 
à criança pouquíssimas opções de uma expansão maior de seu corpo em conjunto com sua mente, restando muitas vêzes as possibilidades únicas de alimentar-se e conversar com colegas. Nesta conjuntura, em nome da aprendizagem, da criança é retirado o direito de ser criança. As brincadeiras passam a ser atividades indesejadas e até mesmo proibidas, relegando-se a um plano ínfimo todo o seu importante papel no desenvolvimento cognitivo, motor,social e emocional da criança.

Assim, a entrada na escola muitas vêzes se constitui num período crítico do desenvolvimento, em virtude das mudanças que acarreta na rotina e no ambiente. $O$ primeiro afastamento prolongado do núcleo familiar, associado à primeira introdução a um grupo formal pré estabelecido, com normas e sistemas de comunicação próprios, são alguns dos aspectos críticos dessas mudanças (Marturano,1977). Assim, não é de se estranhar a ocorrência ou o detectar de desvios no desenvolvimento nesta fase, como bem ressalta Betetto (1987), levando à alta incidência de reprovação e de outros problemas. Estes, entretanto, têm sido estudados mais no que tange a aprendizagem acadêmica, ficando outras áreas em descoberto.

\section{OBJETIVOS}

Este trabalho reflete a busca da autora no sentido de tentar integrar a presente pesquisa com o trabalho que desenvolve junto à Universidade Federal de São Carlos. Em síntese, ele se justifica por focalizar uma área carente de dados, especialmente na realidade brasileira; por viabilizar uma contribuição científica sobre a real função da intervenção preventiva em um ambiente escolar pouco privilegiado e por se inserir dentro do enfoque profissional-pesquisador, gerando da própria ação profissional dados científicos relevantes para a retroinformação da mesma.

Objetivou-se investigar o potencial de um grupo de brincadeiras tradicionais infantis para desenvolver a competência social através de atividades motoras, corporais e de concentração.

Para isso, foi desenvolvida uma programação de brincadeiras adequadas ao desenvolvimento de um grupo de crianças escolares, para serem vivenciadas durante o horário de recreio, no pátio de uma escola rural da região de São Carlos, buscando:

- Promover a vivência de atividades sequenciadas, que dessem a exata noção de suas fases (começo, meio e fim);

- Oferecer a oportunidade de vivenciar atividades que dessem vazão à energia acumulada, dando a elas uma finalidade. Neste caso, por exemplo, as 
corridas e gritos foram inseridos dentro de uma programação e fizeram parte de uma brincadeira;

- Estimular a motivação e a criatividade;

- Estimular a busca, pelas crianças, de novas brincadeiras que pudessem ser vivenciadas dentro dos espaços da escola;

- Estimular os contatos sociais e desenvolver a interação entre os colegas;

- Levantar as mudanças na dinâmica do pátio advindas dessa intervenção;

\section{MÉTODO}

Caracterização da instituição: $O$ trabalho foi conduzido dentro de uma escola rural do município de São Carlos. Na época da intervenção,funcionavam 8 classes de $\mathrm{CB}$ e 2 terceiras séries no período da tarde. Aproximadamente 240 crianças pertenciam a faixa etária compreendida entre os 7 e os 10 anos. Desses, $75 \%$ pertenciam a famílias moradoras da zona rural e $25 \%$ do distrito. A escola está inserida em uma pequena vila de 5.000 habitantes cuja atividade principal é a agricultura,caracterizada basicamente pelo cultivo da cana. As famílias, em geral, envolvem todos os seus membros nas atividades de plantio e colheita, criação de animais, fabricação de farinha,etc.

Observação das atividades no recreio antes da aplicação do programa.

A primeira fase do trabalho consistiu de dez observações realizadas durante o horário de recreio, com a finalidade de identificar a dinâmíca das brincadeiras neste espaço. Pôde-se destacar três grupos de atividades que aconteciam no pátio antes do início da programação: 1) Atividades frequentes;2) Atividades esporádicas e 3) Atividades sem uma finalidade específica.

\section{Atividades Frequentes:}

Havia um número relativamente pequeno de crianças (que oscilava em torno de 20 a 25 alunos) que participava de brincadeiras organizadas. Algumas dessas atividades, como a Amarelinha, Bafo e Bolinha de gude se repetiam com muita frequência, envolvendo sempre os mesmos grupos.

\section{Atividades esporádicas:}

Outras brincadeiras organizadas foram observadas em, no máximo, duas sessões: Passa-anel, Elástico, Pião, Futebol, Gangorra, Mes, Virar estrela, Cobracega, Damas, Brincadeira de roda, Dança da cadeira, Pirulito que bate-bate. Destas brincadeiras participaram grupos diversos que se formavam e se diluiam com uma certa rapidez durante o processo da brincadeira. Parecia faltar algum elemento que mantivesse os grupos envolvidos na brincadeira. As interações 
entre as crianças ocorriam de forma instável e passageira.

\section{Atividades sem uma finalidade específica:}

Destacou-se ainda, com uma frequência muito alta nestes intervalos de aula, um tipo de agrupamento de indivíduos que corriam pelo pátio sem um objetivo aparente; lutas corporais, gritos sem nenhuma inserção em algum contexto. Um trecho do relatório dessas observações, realizado por uma das estagiárias, ilustra a cena que se presenciava:

"Havia muitas meninas correndo e a brincadeira de bater as mãos continuou. Davam chutes nos meninos que tentavam estragar suas brincadeiras. Entre os meninos, estes se chutavam e se batiam. Na hora do sinal, houve muita gritarias, as crianças gritavam também uma no ouvido da outra."

Este dado sugería-nos a hipótese de que existia uma necessidade de ação por parte das crianças, ação esta que não conseguiam direcionar adequadamente, gerando comportamentos sem qualquer possibilidade de se reverter em algo útil para o seu processo de desenvolvimento.

Outra observação que nos chamou a atenção foi a existência de "territórios" masculinos e femininos: áreas do pátio frequentadas exclusivamente por um ou outro sexo. Aí, as meninas participavam de "brincadeiras femininas" (Amarelinha,Mes) e os meninos de "brincadeiras masculinas"(Bolinha de gude, Bafo).

\section{Critérios Estabelecidos para a Condução das Brincadeiras no Pátio}

A fase seguinte a estas observações foi composta de reuniões de preparação da programação. Como um dos objetivos deste trabalho era oferecer opções de lazer para as crianças, entendeu-se que a participação deveria ser livre, ficando completamente a cargo da criança a opção de entrar ou não, de participar de toda a atividade ou de parte dela, de participar de uma ou das tres brincadeiras que estavam sendo conduzidas. Nenhuma atitude dos adultos poderia sugerir a obrigatoriedade de participação.

No planejamento das brincadeiras, houve a preocupação de fazer com que estas exigissem o mínimo de material ou, quando estes faziam parte da atividade, havia sempre a possibilidade de um material mais caro ser substituido por outro de fácil aquisição. Essas alternativas eram levadas às crianças com o objetivo de incentivá-las a praticarem as brincadeiras aprendidas, em outras situações, sem nossa supervisão. Queríamos que, com o tempo, as brincadeiras pudessem acontecer dentro da escola em dias em que não estivéssemos presentes e que as próprias crianças estabelecessem suas regras de comportamento. Queríamos também que elas levassem para casa as idéias adquiridas e ensinassem

Paidéia, FFCLRP-USP, Rib. Preto, Fev/Ago 96. 
outras crianças.

A programação final, além de tomar por base esses pressupostos, ancorou-se especialmente nos trabalhos de Miranda (1989) e de Kishimoto (1992a).

Antes de iniciá-la, cada uma das atividades era analisada segundo sua adequação para aquela população (faixa etária, nível cultural, características de desenvolvimento), a adequação dos materiais e critérios pré estabelecidos, seu potencial motivador e seu potencial para provocar interações entre as crianças e as possíveis adaptações que a atividade poderia sofrer para alcançar este objetivo.

\section{Local}

O espaço do recreio compunha-se de um pátio coberto de aproximadamente $300 \mathrm{~m} 2$, em forma de um $\mathbf{T}$ e um espaço aberto em forma de $\mathrm{U}$, de aproximadamente $1000 \mathrm{~m} 2$, localizado ao redor do pátio coberto. Por se tratar de um espaço mais amplo, optou-se por conduzir a programação no pátio externo da escola, reservando-se o pátio coberto para os dias de chuva. $O$ pátio foi todo mapeado, de forma a criar três espaços distintos para o desenvolvimento das brincadeiras propostas.

\section{Elaboração do programa}

As brincadeiras que compuseram esta programação foram selecionadas segundo as áreas de maior abrangência e tendo por base ítens de um roteiro de análise desenvolvido por Silva e Emmel (1993). Em seguida, estas foram inseridas em três grandes áreas: ATIVIDADES COMPETITIVAS, ATIVIDADES DE CONCENTRAÇÃO e ATIVIDADES CORPORAIS, Estes três tipos foram introduzidos em etapas, sendo as atividades competitivas e de concentração iniciadas num primeiro estágio e as corporais em um segundo momento, após a familiarização das crianças com as coordenadoras de grupos e com a nova proposta de programação que estava sendo inserida no pátio.

No mapeamento do pátio, três espaços foram destacados: 1. para atividades COMPETITIVAS; 2. para atividades de CONCENTRAÇÃO e 3. para atividades CORPORAIS. A intervenção teve uma periodicidade de duas vezes por semana.

Este programa foi elaborado a partir da identificação das atividades 
que mais ocorriam no pátio e das formas inapropriadas de comportamento que foram observadas. Foi possível, com o procedimento adotado, traçar um perfil da dinâmica das brincadeiras que ocorriam dentro daquele espaço e propor uma programação diferenciada que visasse ajudar no desenvolvimento social dos sujeitos e despertar a curiosidade, a criatividade, imaginação e espírito de grupo. As brincadeiras que constaram dessa programação estão listadas na Tabela 1.

Tabela 1- Brincadeiras que compuseram a programação do pátio.

\begin{tabular}{|c|c|}
\hline 1.corrida de saco & 23.lenço-atrás \\
\hline 2.batata quente. & 24.correio \\
\hline 3.cabo de força & 25.ô-dô-lê-cá \\
\hline 4.mãe da rua & 26.uni-duni-tê \\
\hline 5.queimada & 27.elefantinho colorido \\
\hline 6.polícia e ladrão & 28.stop \\
\hline 7.garrafáo & 29.quem está diferente? \\
\hline 8.círculo da sorte & 30.pega-pega com memória \\
\hline 9.rio vermelho & 31.dança das cadeiras \\
\hline 10. bola ao círculo & 32.cabra cega \\
\hline 11.futebol de trapo & 33.balança caixão \\
\hline 12.corrida do jornal & 34.mímica de situaçðes \\
\hline 13.corrida com os pés amarrados & 35.mímica coletiva com 1 líder \\
\hline 14.bola cruzada & 36.quem é o maestro? \\
\hline 15.barra- manteiga & 37.estátua \\
\hline 16.pegador em marcha & 38.morto-vivo \\
\hline 17.rocambole & 39.piso mágico \\
\hline 18.mes & 40.roda \\
\hline 19.telefone sem fio & 41.siga o mestre \\
\hline 20.patativa & 42.duro-mole \\
\hline 21.brincadeira do pisca & 43.passa-anel \\
\hline 22. Boca de leão & \\
\hline
\end{tabular}




\section{Implementação do Programa}

Em cada semestre, seis estagiárias de terapia ocupacional atuaram como coordenadoras dos grupos de brincadeiras no pátio. Cada duas permaneciam em uma área, cabendo a elas convidarem as crianças a participar, explicar o desenvolvimento de cada brincadeira (e demonstrar, caso houvesse necessidade) e coordenar o desenvolvimento das mesmas dentro dos grupos.

\section{Coleta de dados}

Uma outra fase da coleta foi feita durante as sessões definitivas através de filmagens em vídeo. Trinta sessões foram filmadas e posteriormente analisadas. Este trabalho era realizado por uma das estagiárias, que mantinha a câmara móvel enquanto a brincadeira se desenrolava. A cada dia um tipo de brincadeira era filmado (competitiva, de concentração e corporal). As crianças que inicialmente tinham na câmara filmadora uma novidade, foram aos poucos incorporando sua presença ao ponto desta não interferir no seu desempenho. $O$ conteúdo observado era registrado em um protocolo que continham as informações de maior relevancia para as análises: no. de participantes no início e no final, no. de meninos; no. de meninas; observações quanto à forma de interação usada com os pares e no. de vezes em que a atividade foi repetida ( no de partidas). Observações adicionais de interesse eram registradas manualmente logo após cada sessão de brincadeira.

Os dados de frequência de participação forneceram os elementos para análise da motivação. Alto número de participantes, no geral, coincidia com alto grau de motivação; baixa frequência, ao contrário, estava relacionada com baixa motivação, com brincadeira desinteressante e que passou por uma reavaliação.

\section{Avaliação da Programação}

Durante as férias de julho das crianças foi realizada uma primeira avaliação da programação aplicada, preparando a fase seguinte, com a duração de mais um semestre letivo. Para esta segunda fase, as brincadeiras que causaram baixos índices de participação foram excluídas, outras sofreram reformulações no seu método de aplicação e as que apresentaram alta motivação voltaram a ser oferecidas. Além disso, novas brincadeiras foram introduzidas, cabendo o acolhimento às sugestões de brincadeiras das próprias crianças. 


\section{RESULTADOS E DISCUSSÃO}

\section{Situação do Pátio}

As observações feitas antes da introdução da proposta aqui delineada mostraram que o pátio apresentava uma dinâmica muito semelhante todos os dias. Havia um período inicial, que durava entre cinco e dez minutos, onde as crianças tomavam a merenda. Poucas sentavam-se à única mesa que havia no pátio. A grande maioria se alimentava segurando o prato nas mãos, andando ou mesmo correndo. Após este período, o pátio era tomado por crianças correndo sós ou de mãos dadas, andando ou brincando. Havia poucas opções de brincadeiras. Uma única amarelinha riscada no chão era bastante utilizada, principalmente pelas meninas. As brincadeiras que predominavam entre os meninos eram o "Bafo", "Bolinha de Gude" e Lutas corporais. Algumas meninas realizavam uma brincadeira semelhante a "mamãe e filhinha": a maior segurando a mão da menor e andando pelo pátio assim. Havia uma nítida separação entre meninas e meninos e o contato com o sexo oposto, quando existia, ocorria de forma agressiva ( provocações e/ou empurrões).

Ao toque do sinal de final do recreio, aumentavam os gritos e as correrias pelos espaços da escola.

\section{Resultados relativos ao comportamento social das crianças}

Os primeiros resultados foram sendo observados logo nas primeiras semanas de aplicação da programação proposta. $O$ número de crianças que participou das atividades foi crescente a cada sessão. Ao mesmo tempo que aumentou a participação, ocorreu uma maior organização dos grupos. Esta constatação indicava que o espírito de cooperação, a iniciativa e a interação social começavam a fazer parte dessa dinâmica.

O espaço coberto do pátio se esvaziou durante os dias de brincadeira ao ar livre e as correrias e gritos diminuíram consideravelmente.

\section{A Questão dos "Territórios".}

A existência de áreas do pátio reservadas a brincadeiras para grupos de meninos e de meninas separadamente dificultava não só a interação meninos/ meninas, como também restringia as áreas de circulação do pátio. Embora entendendo que parte desse comportamento se justificava pelas próprias características que envolvem as crianças na fase de pré adolescência (onde se formam grupos separados por sexo), entendeu-se que este comportamento deveria ser suavizado, a fim de não limitar tanto locais de acesso e possíveis contatos 
meninos/meninas. Para isso, buscou-se "abrir" as áreas destinadas ao desenvolvimento das brincadeiras, utilizando os "territórios" como espaços do programa, destinados a participação tanto de meninos como de meninas.

\section{Resultados relativos ao Programa de Atividades}

No total, 43 novas brincadeiras foram introduzidas, sendo $17 \mathrm{com}$ características acentuadamente Competitivas, 14 de Concentração e 12 Corporais.

É difícil estabelecer um número preciso de participantes em função da grande rotatividade dos membros dentro de várias partidas de uma mesma brincadeira e entre as várias atividades que estavam ocorrendo ao mesmo tempo. Frequentemente as mesmas crianças participavam de várias partidas de uma mesma brincadeira, ou, tendo participado de uma partida em um dos espaços, corria até o outro para entrar em outra brincadeira. Mesmo assim, considerando o número médio de participantes em cada partida, pode-se estimar que das 240 crianças que cursavam o C.B., cerca de $85 \%$ a $90 \%$ participou das atividades do projeto.

$\mathrm{Na}$ Tabela 2 é apresentado o número médio de participantes por cada tipo de brincadeira.

Tabela 2 - Número de participantes em cada tipo de brincadeira

\begin{tabular}{|c|c|c|c|c|c|}
\hline Tipo & \multicolumn{2}{|c|}{ Meninos } & \multicolumn{2}{c|}{ Meninas } & Total \\
& $\mathbf{N}$ & $\mathbf{\%}$ & $\mathbf{N}$ & \\
\hline Competitivas & 229 & $\mathbf{6 4 , 2}$ & 128 & 35,8 & 357 \\
\hline Concentração & $\mathbf{8 8}$ & 36,4 & 154 & $\mathbf{6 3 , 6}$ & 242 \\
\hline Corporais & 101 & 47,9 & 110 & $\mathbf{5 2 . 1}$ & 211 \\
\hline
\end{tabular}

Na somatória de todas as brincadeiras vivenciadas, o número médio total de participantes foi, respectivamente: 357 nas brincadeiras Competitivas, 242 nas de Concentração e 211 nas Corporais. Apesar do total de crianças na faixa etária mencionada ser menor, aqui foram computadas as várias partidas ocorridas em uma mesma brincadeira, onde uma mesma criança poderia participar novamente.

Outro resultado que se destaca da Tabela 1 diz respeito à participação de meninos e meninas nos três tipos de brincadeiras oferecidos: as atividades Competitivas atraíram mais os meninos $(64,2 \%$ X $35,8 \%$ de meninas participando) e as de Concentração chamaram mais as meninas $(63,3 \% \times 36,4 \%$

Paidéia, FFCLRP-USP, Rib. Preto, Fev/Ago 96. 
de meninos participando), em diferenças proporcionais significantes. As atividades Corporais tiveram a participação de ambos os sexos de uma maneira mais equilibrada (47,9\% meninos e $52,1 \%$ meninas). Uma das hipóteses para explicar estas preferências está no tipo de brincadeira: as Competitivas referiamse a brincadeiras que exigiam maior atividade motora do que as de Concentração. É sabido que os meninos nesta faixa de idade concentram sua energia mais em atividades motoras, sentindo-se atraídos por brincadeiras mais agressivas, onde possam colocar à prova e exibir suas capacidades físicas. Enquanto isso, as meninas desta idade estão mais voltadas para atividades menos agressivas.

Outra explicação pode estar ligada às áreas reservadas para cada tipo de brincadeira. Mais uma vez a questão dos "territórios" é levantada. As atividades Competitivas foram inicialmente desenvolvidas na área onde permaneciam os meninos e as de Concentração naquela antes ocupada pelas meninas. Para as atividades Corporais foi aberto um espaço novo, que não era muito usado pelas crianças da escola. Com a programação de brincadeiras introduzida, embora estes espaços tenham sido abertos à utilização de ambos os sexos, possivelmente algumas crianças tenham mantido ainda o conceito de que "o espaço do outro" não deveria ser invadido. No momento em que isso foi constatado, utilizou-se como estratégia a programação cruzada de brincadeiras nestes espaços. Assim, por exemplo, onde tradicionalmente se juntavam os meninos para as partidas de Bolinha de Gude, introduziu-se, por um período, brincadeiras que se convencionou chamar de "femininas", como por exemplo Lenço-Atrás. Ainda que tivessem permanecido nítidas as preferências sexuais, de um modo geral a interação entre os parceiros sofreu uma mudança qualitativa nitida; diminuindo sobremaneira a separação entre os sexos durante as brincadeiras. Locais onde antes não eram pisados por um dos sexos, passou a ser assistido ou dividido entre meninos e meninas.

Um outro dado de interesse para este estudo diz respeito às brincadeiras preferidas pelas crianças. Ao final da primeira sessão de cada jogo, cinco crianças eram escolhidas aleatoriamente para externar sua opinião sobre a brincadeira que acabara de vivenciar. Em uma filipeta, ela respondia à seguinte pergunta:

"O que você achou da brincadeira que acabou agora?

Super Legal ()

Legal ( )

Mais ou menos ( )

Não Gostei ( )"

Paidéia, FFCLRP-USP, Rib. Preto, Fev/Ago 96. 
As respostas foram catalogadas com a seguinte correspondência:

Super Legal $=$ Excelente $=\mathbf{E}$

Legal $=$ Bom $=\mathbf{B}$

Mais ou Menos $=$ Regular $=\mathbf{R}$

Não Gostei $=\mathbf{N}$

Os resultados confirmam a adequação do programa de atividades que foi proposto. Segundo as avaliações das crianças, a grande maioria das brincadeiras escolhidas ganhou a aprovação da clientela à qual foi destinada.

Conforme registrado anteriormente, as brincadeiras mais apreciadas pelas crianças no primeiro semestre fizeram parte da programação do segundo semestre. Foram elas: Cabo de Força, Mãe da Rua, Bola Cruzada, BarraManteiga, Mes, Mímica de Situações, Quem é o Maestro, Quem está diferente?, Garrafão, Círculo da Sorte, Boca de Leão, Futebol de Trapo, Patativa, Brincadeira do Pisca, Lenço-atrás, O-Do-Lê-Cá, Uni-Duni-Tê, Elefantinho Colorido, Pega-Pega com Memória, Dança das Cadeiras Balança-Caixão, Mímica Coletiva com um Líder, Estátua, Morto-Vivo, Siga o Mestre, DuroMole, Passa-Anel, Amarelinha, Alí-Babá e Dança do Geb-Geb.

Vale destacar aqui que as atividades que envolveram movimentação corporal ampla com um grau relativo de competitividade entre grupos parecem ter atraído sobremaneira a atenção das crianças. Círculo da Sorte, Futebol de Trapo, Mãe da Rua e Cabo de Força são exemplos dessa afirmação.

As brincadeiras que foram incorporadas à programação por sugestão das crianças foram: Pular corda; Amarelinh; Brincadeira de roda; Beijo, abraço aperto de mão; Alí-Babá.

Algumas atividades não despertaram o suficiente interêsse da maioria das crianças, anulando seus efeitos como estimulantes da aprendizagem e por esta razão foram retiradas da programação. Foram elas: Telefone sem fio, Rio Vermelho, Correio e STOP. Acredita-se que os motivos desse desinterêsse estejam ligados a própria dinâmica das brincadeiras, que não foram adequadas a grandes grupos de crianças, como era geralmente o caso neste trabalho. Estas atividades, exigiam: ou memorização de um grande número de informações, memorização sequencial ou a demora excessiva para chegar sua vez de jogar. Talvez a soma desses aspectos tenha contribuído para o desinterêsse da maioria.

Na brincadeira Telefone sem Fio, houve a participação de grupos muito heterogêneos, com crianças muito grandes e muito pequenas juntas. Isso dificultava a compreensão das palavras que eram "assopradas" no ouvido e geraram o desinterêsse, principalmente das crianças mais novas. Aos poucos,

Paidéia, FFCLRP-USP, Rib. Preto, Fev/Ago 96. 
estas iam se retirando da área de atividade, deixando os que permaneciam numa situação de terem que recomeçar.

Foi interessante observar que na brincadeira de MíMICA a proposta inicial não havia gerado o interesse das crianças. Estas se sentiam acanhadas por serem injetadas muito bruscamente em uma situação de exposição de sua expressão corporal e se retiravam. Decidiu-se então fazer uma graduação dessa entrada, introduzindo a criança, inicialmente junto com o adulto executando a mímica. Neste primeiro momento, a participação das crianças se restringia a tentar adivinhar o significado da mímica executada pelo adulto. A partir daí, estas entravam junto com o adulto e assim paulatinamente até o jogo ser feito só entre as crianças. Essa revisão permitiu não só que a motivação pela atividade retomasse um nível muito alto, como também um grande avanço na desinibição e na plasticidade corporal das crianças, que passaram a, inclusive; criar motivos de mímica de complexidade crescente.

Conforme apontado anteriormente, fatores culturais constituem importantes variáveis que afetam o comportamento de brincar. A riqueza da brincadeira de Mímica para o desenvolvimento da criança foi observada ainda pela sua capacidade em fazer com que estas transpusessem cenas de seu cotidiano para a brincadeira. Quando a atividade entrou na fase das crianças sugerirem temas para serem expressos corporalmente, cenas bem próprias daquela comunidade vieram à tona, desvendando todo um universo próprio daquela cultura. Muitas das sugestões de mímica dadas pelas crianças revelavam o diaa-dia de quem vive em uma comunidade rural como aquela: "carpir", "plantar árvore", "pescar", "atirar com estilingue","tirar leite de vaca", "tirar chapéu e pendurar no cabide", "subir no cavalo e galopar", "semear", "descascar milho", "acender fogão a lenha", "tosquear carneiro". Esta característica da brincadeira e seu poder de revelar a cultura de um povo foi mencionado em um trabalho de antropologia social estudando os índios Juruna do Alto Xingu. Constatou-se que uma das brincadeiras mais comuns das crianças da aldeia , durante a seca, é a de correr atrás ou atirar paus nos animais que criam, imitando a atividade de caça dos adultos; brincam de lutar e têm pequenos arcos e flechas. As meninas brincam de fiar em fusos pequenos, fazer panelas de barro. Seus cantos de roda são imitação dos rituais de sua tribo e de outros grupos tribais (Oliveira, 1986). Sua relação com a brincadeira de Mímica reforça este potencial da brincadeira.

$\mathrm{Na}$ verdade, o que se observou na situação aqui colocada, foi a própria transposição das experiências de vida daquelas crianças. Quem sabe, se estivéssemos dentro de um meio urbano, as sugestões não estariam ligadas a computadores, ou carros, etc?

Ainda como resultado do programa de brincadeiras que foi estudado no

Paidéia, FFCLRP-USP, Rib. Preto, Fev/Ago 96. 
presente trabalho, observou-se $o$ aparecimento de novas brincadeiras, trazidas pelas crianças, bem como a repetição daquelas aprendidas fora dos dias de funcionamento do projeto.

No final do ano, algumas das brincadeiras que mais motivaram as crianças foram pintadas no chão do pátio e deixadas para as crianças brincarem sòzinhas: Amarelinha, Garrafão, Boca de Leão e Círculo da Sorte.

\section{CONCLUSÕES}

Esse projeto teve uma receptividade bastante grande, tanto por parte da escola, como da comunidade regional. Os resultados obtidos permitem-nos afirmar que a intervenção foi positiva e alcançou os objetivos a que se propôs este trabalho.

A vivência oferecida favoreceu a introdução de conceitos que serão imediatamente transpostos para a vida cotidiana das crianças, como conceitos numéricos, de cores, formas, além do esquema corporal, atenção, imaginação e criatividade.

Como afirma Brougère (1995), o brinquedo, a brincadeira é portadora de uma multiplicidade de relações em potencial. Neste trabalho, a atividade de brincar mostrou ser de uma possante ajuda no relacionamento entre a criança e o meio ambiente, a criança e outra criança. Isto se deve ao fato de que a brincadeira, enquanto intermediária da relação social, pode eliminar as tensões do primeiro contato com o outro, que às vêzes é tão sofrido para a criança fazer acontecer, quando depende somente de seu esforço pessoal. Neste sentido, a atividade age por si só, fornecendo os meios para que a interação ocorra da forma mais suave e adequada possível.

A participação das crianças nas brincadeiras em grupos foi crescente. Isto estimulou a formação de novas amizades e o desenvolvimento de novas formas de contato com o outro. O reflexo dessa mudança foi sentido no comportamento geral do pátio. Já no final do primeiro semestre podia-se observar e ver relatados pelos professores e inspetores de alunos a diminuição nas gritarias e correrias pelo pátio.

Por outro lado, a relevância da atuação do terapeuta ocupacional dentro do espaço escolar como promotor de um melhor ambiente para as crianças ficou clara com este trabalho. Consequentemente, sua contribuição na promoção do desenvolvimento sadio de escolares foi demonstrada através dos resultados obtidos.

No entanto, acredita-se que estes resultados seriam mais contundentes se houvesse condições de uma programação mais intensiva dentro da escola e 
extensiva a outras instituições de ensino. Uma programação desse tipo que estivesse inserida dentro dos objetivos de cada escola da rede pública certamente traria benefícios para o desenvolvimento harmônico das crianças, como ficou demonstrado.

Ficou claro que este é um espaço perdido dentro da escola, no qual não se pensa e nem existe preocupação em programá-lo para o lazer. Este trabalho mostrou que essa preocupaçãp significa um investimento importante para a educação. É necessário que as escolas comecem a pensar seriamente no intervalo do recreio de seus alunos, como um espaço importante de aprendizagens. Esta afirmação torna-se mais forte quanto menos privilegiada for a população que se pretende atingir. Pode-se inferir até que culturas que não dispõem de espaços alternativos de brincadeiras, têm maior urgência para vivenciar programas dessa natureza.

\section{REFERENCIAS BIBLIOGRÁFICAS}

BETETTO, A.M.B.S.(1987) Alfabetização de crianças com atraso no desenvolvimento através da instrução programada e treinamento em serviço de professores.S.P. IPUSP. (Tese de Doutorado)

BIASOLI - ALVES, Z. M., SIMIONATO - TOZO, S. M. P.(1992) O brincar para as crianças da década de 80. Cadernos de Terapia Ocupacional da UFSCar, São Carlos, v. 3, n 2, p. 107-119.

BRANCO,A.M.C.U. (1989) Socialização na pré-escola: o papel da professora e da organização das atividades no desenvolvimento de interações entre crianças. S,P. IPUSP (Tese de Doutorado)

BROUGËE, G.(1995) Brinquedo e cultura. Tradução de Gisela Wajskop. São Paulo : Cortez.

EMMEL, M.L.G.(1990) Interação Social: a função da atividade. São Paulo : IPUSP, (Tese de Doutorado)

HAVIGHURST, R.J.(1953) Human development and education. New York, David Mckay Co., Inc.

JONES,N.B. (1981) Estudos etológicos do comportamento da criança. Tradução de Emma Otta. S.P. Livraria Pioneira Editora.

KISHIMOTO,T.M. (1992) O jogo, a criança e a educação. São Paulo : USP, (Tese de Livre-Docência.)

(1992a) Jogos Tradicionais Infantis do Brasil. Vol 1 a 8. FEUSP/FAPESP. S.P.

MARTINEZ, C.M.S.(1992) Atividades e brincadeiras na vida da criança com problemas no desenvolvimento no ínicio dos anos 90: a visão dos pais. São Carlos : UFSCar (Dissertação de Mestrado.) 
MARTURANO, E.M.(1977) Características do comportamento durante o primeiro ano de frequência ao jardim da infância.USP-Rib. Prêto. (Tese de Livre docência).

MIRANDA,N.(1989) 200 jogos infantis. Belo Horizonte. Ed. Itatiaia.

PIAGET, J.(1973) A formação do símbolo na criança: imitação, jogos, sonhos, imagem e representação. Tradução de Álvaro Cabral e Christiano M. Oiticica. 3ed. Rio de Janeiro : Zahar.

PIERRE, S.A., KUBO, A.M.(1990) Brinquedos e brincadeiras no desenvolvimento infantil. In: KUBO, A.M. et al. Fisioterapia, Fonoaudiologia e Terapia Ocupacional em Pediatria. São Paulo : Savier.

SILVA,C.C.B. \& EMMEL,M.L.G.(1993) Jogos e brincadeiras: roteiro de análise de atividades para o terapeuta ocupacional. Cadernos de Terapia Ocupacional da UFSCar. 4(1-2),p.46-62.

\section{ABSTRACT}

This study had as its main objective to analyse the interactions between school children so it could be possible to propose and realize a program with joke activities in the yard of a Rural School in the State of São Paulo.200 children from 7 to 10 years old. During one year these children had oriented activities in the recreation time.The results indicate that such program brings many advantages changing the anti-social behavior of children in the playground and also in the classroom.

Key-words:Social interaction, Activities in the play-ground

Palavras-Chave: Brincadeira, Interação social; Análise de atividades, Escola. 